\title{
The attention network test: a characteristic pattern of deficits in children with ADHD Steinunn Adólfsdóttir*1, Lin Sørensen ${ }^{1,2}$ and Astri J Lundervold ${ }^{1,2}$
}

\author{
Address: ${ }^{1}$ Department of Biological and Medical Psychology, The Faculty of Psychology, University of Bergen, Jonas Lies vei 91, 5009 Bergen, \\ Norway and ${ }^{2}$ Centre for Child and Adolescent Mental Health, University of Bergen, John Lunds plass 3, 5020 Bergen, Norway \\ Email: Steinunn Adólfsdóttir* - steinunn.adolfsdottir@psych.uib.no; Lin Sørensen - lin.sorensen@psych.uib.no; \\ Astri J Lundervold - astri.lundervold@psych.uib.no \\ * Corresponding author
}

Published: 12 February 2008

Behavioral and Brain Functions 2008, 4:9 doi:10.1 186/1744-908I-4-9
Received: 25 April 2007

Accepted: 12 February 2008

This article is available from: http://www.behavioralandbrainfunctions.com/content/4/I/9

(c) 2008 Adólfsdóttir et al; licensee BioMed Central Ltd.

This is an Open Access article distributed under the terms of the Creative Commons Attribution License (http://creativecommons.org/licenses/by/2.0), which permits unrestricted use, distribution, and reproduction in any medium, provided the original work is properly cited.

\begin{abstract}
Background: The Attention Network test (ANT) gives measures of different aspects of the complex process of attention. We ask if children with Attention Deficit Hyperactivity Disorder (ADHD) will show a characteristic pattern of deficits on this test.

Methods: The sample included 157 children ( $M=10$ years) who performed the child version of ANT as participants of the Bergen Child Study. Children with an ADHD diagnosis $(\mathrm{N}=45)$ were compared to a group of children with other diagnoses $(N=55)$ and a group of children without any diagnosis $(\mathrm{N}=57)$.

Results: The group of children with ADHD showed low accuracy scores and a variable response set, indicating an inattentive response style. No differences were found between the groups on RT and accuracy measures of the alerting, orienting, and conflict networks. A high correlation between full scale IQ (FSIQ) and ANT measures was only found in the ADHD group. When FSIQ score was included as a covariate, the group differences were not statistically significant on any ANT measure.

Conclusion: The present study showed that accuracy and variability measures rather than measures of the three attention networks conveyed the characteristic pattern of deficits in children with ADHD. The results emphasized the importance of including these measures to extend the sensitivity of the ANT, and the importance of reporting results both with and without FSIQ as a covariate.
\end{abstract}

\section{Background}

Attention is a complex cognitive function, dependent on interacting neural systems of the brain. According to the Attention Network theory the systems can be subdivided into an alerting or vigilance network, a network of orientation or selection, and an executive or conflict network [1]. A range of experimental, neuroimaging, and clinical studies have supported the theory [2-4] and Berger and Posner [5] as well as Fan et al. [6] have argued that the attention network model is of special interest in studies of attentional disorders, e.g. the Attention Deficit Hyperactivity Disorder (ADHD).

The three networks have been widely explored by using cue-target reaction time (RT) tasks [7] and tasks evoking a conflict (e.g. [8]). Recently, Fan, Posner and collaborators [6] developed an experimental task called the Attention Network Test (ANT), combining a cue-target and a flanker 
test to obtain measures of the efficiency and accuracy of the three networks. Recent studies have used different versions of ANT to study cognitive characteristics associated with ADHD. Booth [9] used the original child version and found no differences between children with ADHD and control children on any of the three networks. An Event Related Potential (ERP) study by Rodriguez [10] demonstrated a deviant ERP activation pattern on the alerting and conflict networks in young adults with the DSM-IV defined inattentive subtype of ADHD. A deviant activation pattern was also found in a Functional magnetic resonance imaging (fMRI) study by Konrad and colleagues [11]. This affected all three networks, but the behavioral data showed that only the conflict network was less efficient in ADHD children than in control children. These results suggest that the neural basis of the attentional networks may be affected in children with ADHD, even when this is not reflected in behavior measures.

Most studies using ANT have focused on the RT measures of the three attention networks, even though studies using measures from continuous performance tasks have shown that accuracy measures are more affected than RT measures in children with ADHD $[12,13]$. Furthermore, children with ADHD are shown to be impaired on measures of sustained attention and vigilance $[12,14,15]$, they show a more variable RT and report more errors of omissions and commissions than their non-ADHD peers $[16,17]$. Most studies reporting such findings have used the Continuous Performance Test (CPT). A recent study by Oberlin et al. [18] included variability and error measures in their analysis of ANT results. They found that these measures discriminated adults with ADHD from controls. As far as we know, no study has generated error and variability measures from ANT in a study of children with ADHD.

The aim of the present study was to find characteristic patterns of ANT results in children with ADHD by including measures of error types and variability in addition to the conventional measures of the three attention networks (Table 1). From earlier studies we assumed that the conflict network was affected in children with ADHD. Furthermore, we expected the extended measures to add information about behavior characteristics of the ADHD group, i.e. we expected to find lower accuracy scores and higher response variability in children with ADHD than in their non-ADHD peers.

\section{Methods \\ Participants}

The present study is part of the Bergen Child Study (BCS). The protocol and population of the stages in the first wave of BCS are described in detail in separate publications $[19,20]$, and only a short presentation will be given here. Briefly, the original BCS included three stages: screening for behavior problems and psychiatric disorder of the whole Bergen 7-9-year-old population using the Strengths and Difficulties Questionnaire (SDQ) [21], the Autism Spectrum Screening Questionnaire (ASSQ) [22], and items pertaining DSM-IV symptoms of ADHD and ODD from Swanson, Nolan, and Pelham, version IV (SNAP-IV) [23], supplemented with a number of items designed specifically for use in the BCS (stage 1); Development and Well-Being Assessment (DAWBA) [24] interviews with parents of children defined as screen positive in stage 1 and a sample of screen negative children (stage 2), and indepth neuropsychiatric/neuropsychological assessment of

Table I: Definition of variables

\begin{tabular}{|c|c|}
\hline Variable & Definition \\
\hline Reaction time & Mean reaction time (RT) for each cue and flanker condition \\
\hline Hits & Number of correct responses \\
\hline Overall errors & Number of overall errors \\
\hline Wrong responses & All other error responses than omissions, perservations and outliers \\
\hline Omissions & $\mathrm{RT}=0 \mathrm{~ms}$ \\
\hline Perservations & $\mathrm{RT}>0 \mathrm{~ms} .<100 \mathrm{~ms}$ \\
\hline Outliers & $\begin{array}{l}\text { Flanker } \times \text { Cue RT }- \text { Stdev }<3 * \text { Stdev. RT }=0 \text { can not be both omission and outlier and priority was given to } \\
\text { omissions }\end{array}$ \\
\hline Hits RT & Median RT for correct responses \\
\hline Hits RT SE & Standard error of RT for correct responses. Measure of consistency of responses \\
\hline Variability of SE & $\begin{array}{l}\text { Standard deviation of the } 3 \text { standard error values calculated for each block. Measures within respondent } \\
\text { variability }\end{array}$ \\
\hline Hits RT block change & The slope of change in RT between blocks. Measure of vigilance \\
\hline Hits SE block change & The slope of change in standard error of RT between blocks. Measure of consistency and vigilance \\
\hline \multirow[t]{4}{*}{ Attention Networks } & Calculated both for RT and errors: \\
\hline & Alerting $=\mathrm{RT} / \mathrm{error}$ for no cue $-\mathrm{RT} / \mathrm{error}$ for double cue \\
\hline & Orienting $=\mathrm{RT} /$ error for central cue $-\mathrm{RT} /$ error for orienting cue \\
\hline & Conflict: = RT/error for incongruent flanker - RT/error for congruent flanker \\
\hline
\end{tabular}


a subsample of "DAWBA positive" (i.e. children who obtained a diagnosis according to DAWBA) and "DAWBA negative" children from stage 2 . Children with a "chronic somatic disorder" reported by parents in stage 1 of the study [25] were included, regardless of participation in stage 2.

The aim of stage 3 was to investigate the neuropsychological function (motor, emotional and cognitive) of children with known mental health problems and normal controls. A total of 329 children met together with their parents for a 6 hours examination procedure at the Neuropsychology outpatient clinic at the University of Bergen. The examination included a diagnostic semi-structured interview of parent and child (Kiddie-Sads-Present and Lifetime Version) [26]; the Wechsler's Intelligence Scale for Children, third version (WISC-III) [27], and the AANT [28]. Of the 286 children who completed the ANT with an accuracy scores above 50\%, all children with a diagnosis in remission $(\mathrm{N}=8)$ and the group of children with
Oppositional Defiant Disorder (ODD) without ADHD (N $=11$ ) were excluded. The last group was excluded due to the overlap in symptomatology. The final sample $(\mathrm{N}=$ 157 ) included all children with a definite ADHD diagnosis $(\mathrm{N}=45)$, children with other definite diagnoses $(\mathrm{N}=$ $55)$, and children without any diagnosis or ADHD symptoms $(\mathrm{N}=57)$ (Figure 1$)$. The ADHD group was further divided into a group of children taking central stimulants at the inclusion of the study $(\mathrm{N}=9)$ and children not taking any central stimulants $(\mathrm{N}=36)$. The last group included mainly newly diagnosed children. All children taking central stimulants had an ADHD diagnosis at the entry of the study, and their parents were asked to withhold the medication on the day of clinical examination. Because of the low number of girls in the ADHD group $(\mathrm{N}$ $=13$ ), gender differences were not investigated in the present study.

The study was approved by the Regional Committee of Ethics on Medical Research in Western Norway and by the

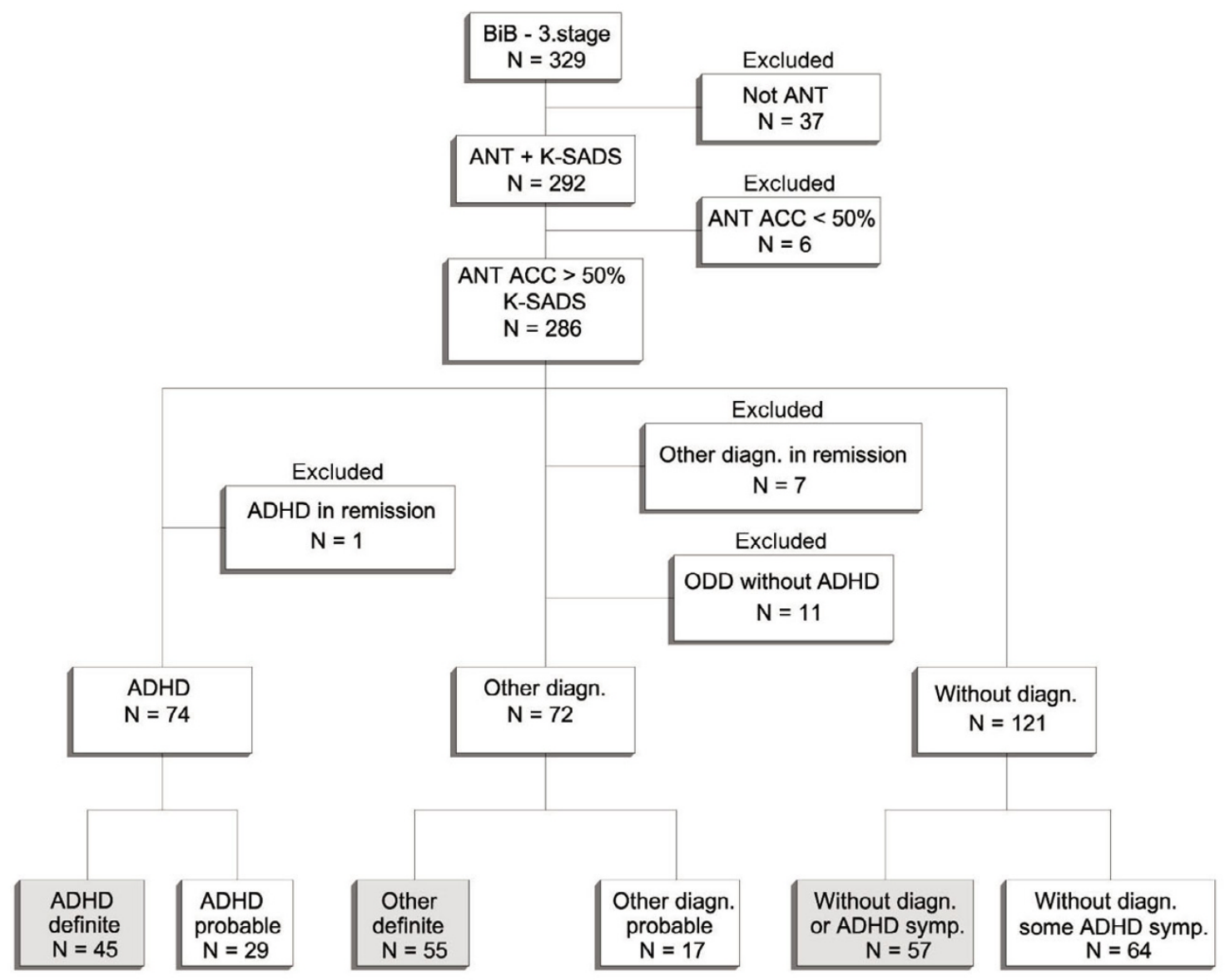

\section{Figure I}

Flow chart visualizing the selection procedure. 
Ombudsman for Privacy in Research, Norwegian Social Science Data Services Ltd.

\section{Measures}

Kiddie-Sads-Present and Lifetime Version (Kiddie-Sads-PL) [26] was used as a diagnostic instrument. Kiddie-Sads-PL is a reliable semi-structured interview designed to evaluate current and past episodes of psychopathology in children according to the DSM-IV criteria [26,29]. The diagnosis was ascertained through an interview in two separate sessions on the same day, first with one or both of the parents and then with the child. Diagnoses were scored by the interviewer immediately after the assessment of both informants as either definite, probable ( $\geq 75 \%$ of symptom criteria met), in remission, or not present [26].

The ANT used in the present study is the original "child version" [30] downloaded from Jin Fan's webpage [28]. The test has four cue conditions (no cue, center, double, orienting) and three flanker conditions (congruent, incongruent, neutral), and has been described in detail elsewhere [30,31]. All combinations of conditions are randomly presented in three blocks of 48 trials each. Overview of the calculations used in the present study is given in Table 1. The calculated measures are based on an Excel macro downloaded from Jin Fans webpage [28], supplemented by measures calculated according to the formulas given by Conners and collaborators [32]. This file was imported into SPSS 13.0, which was used for all further analyses.

WISC-III [27] was used to assess intellectual function. The Full Scale IQ (FSIQ) was included in the present study, with scaled scores derived from Swedish norms [33].

\section{Procedure}

The clinical examination was performed in an outpatient clinic at the University of Bergen. Trained psychologists administered the Kiddie-Sads-PL interview. The WISC-III and the ANT were administered by trained test-assistants, in a quiet room designed for testing. It was run on E-Prime software, on a stationary computer with a 17 " computer screen. The children sat at a comfortable distance from the screen and used left and right thumb to press the left or the right mouse button, corresponding to a left and right pointing fish. The children were instructed to help feed the hungry fish as fast as they could by pushing the left or right button, according to which direction the fish was pointing. They were told that sometimes the fish would appear alone, and other times it would swim together with other fishes. In all cases, they were told to concentrate on the fish in the middle. They were also asked to keep their eyes on the fixation point during the presentations. The completion time was approximately $25 \mathrm{~min}-$ utes.

\section{Statistical analysis}

A Pearson correlation analysis with Bonferroni correction was computed, including the FSIQ score, age, and ANT measures. For FSIQ score, age, network measures, error measures, RT, standard error (SE) of RT, variability of SE, and vigilance measures, separate one-way between-groups ANOVAs were calculated. Main effects were further explored with post-hoc tests. The Tukey HSD was used to explore differences between groups where equivalence of variances were assumed, and the Games-Howell test was used if variances were heterogeneous. Bonferroni corrected independent-samples t-test was used to compare the results of children in the ADHD group who regularly took central stimulants and the results of the non-medicated children in the same diagnostic group.

\section{Results Age and FSIQ scores}

The age range of the participants was 7.9 to 11.9 years, with a mean age of 10 . A one-way ANOVA showed a statistically significant difference between the three diagnostic groups in age, $F(2,154)=3.311, p=.039$, but Tukey HSD between group comparison revealed that the difference between the ADHD group and the other groups only bordered on significance (other diagnoses: $p=.07$; without any diagnosis: $p=.06$ ). The mean FSIQ score for all participants was 90.9 (Table 2). A one-way ANOVA revealed a statistically significant difference between the groups on the FSIQ measure, and a Games-Howell posthoc test showed that the ADHD group obtained significantly lower FSIQ scores than the non-ADHD groups (Table 2 and 3 ).

\section{Attention Networks}

A one-way between groups ANOVA revealed no statistically significant differences between the three diagnostic groups on the RT and error measures of the three attention networks (Table 2 and 3).

\section{Error measures}

The overall accuracy on the ANT was $90.7 \%$, and an analysis of the overall number of errors showed that $97.0 \%$ of all errors were wrong responses and omissions (Table 2). Outliers and perservations represented only 3.0\% of all errors and less than $1 \%$ of all responses, and were not included in further analyses. A one-way between groups ANOVA of the remaining error measures showed a statistically significant main effect of group (Table 3). A GamesHowell post-hoc test revealed statistically significant higher overall error scores in the ADHD group than the non-ADHD groups, with significantly more wrong responses than the non-ADHD groups (Table 2 and 3). The number of omission errors was also higher in the ADHD group than in the non-ADHD groups, but the differences were not statistically significant (compared to the 
Table 2: Means and SDs of the ADHD and non-ADHD groups on demographic variables and selected ANT variables.

\begin{tabular}{|c|c|c|c|c|}
\hline & ADHD definite diagnosis $N=45$ & Other definite Diagnoses $N=55$ & Without diagnosis $N=57$ & Overall $\mathrm{N}=157$ \\
\hline & RT/Error M (SD) & RT/Error M (SD) & RT/Error M (SD) & RT/Error M (SD) \\
\hline \multicolumn{5}{|l|}{ FSIQ and age } \\
\hline FSIQ & $78,7(17,6)$ & $93,6(15,2)$ & $97,8(11,5)$ & $90,9(16,7)$ \\
\hline Age & $10,3(0,8)$ & $9,9(1,0)$ & $9,9(0,9)$ & $10,0(0,9)$ \\
\hline \multicolumn{5}{|c|}{ Accuracy and error variables } \\
\hline Hits & $125, \mid(16,7)$ & $132,4(8,6)$ & $|33|,(9,7)$ & $130,6(12,2)$ \\
\hline Overall errors & $18,9(16,7)$ & $11,6(8,6)$ & $10,9(9,7)$ & $13,4(12,2)$ \\
\hline Wrong response & $5,4(4,5)$ & $3,3(3,3)$ & $3,2(3,3)$ & $3,9(3,8)$ \\
\hline Omissions & $12,9(14,6)$ & $7,9(7,1)$ & $7,3(7,9)$ & $9,1(10,3)$ \\
\hline Perservations & $0,2(0,5)$ & $0,1(0,3)$ & $0,1(0,2)$ & $0,1(0,4)$ \\
\hline Outliers & $0,3(0,6)$ & $0,3(0,5)$ & $0,3(0,8)$ & $0,3(0,7)$ \\
\hline \multicolumn{5}{|c|}{ Consistency and variability variables } \\
\hline Hits RT & $828,3(148,4)$ & $791,9(123,7)$ & $791,8(124,7)$ & $802,3(131,8)$ \\
\hline Hit RT SE & $22,5(5,6)$ & $20,2(4,1)$ & $19,7(5,0)$ & $20,7(5,0)$ \\
\hline Variability of SE & $5,2(2,9)$ & $5,4(2,4)$ & $5,3(3,8)$ & $5,3(3,1)$ \\
\hline Hit RT Block Change & $-3,1(48,9)$ & $-27,8(52,7)$ & $-13,9(66,7)$ & $-15,7(57,7)$ \\
\hline Hit SE Block Change & $0,3(4,9)$ & $-0,1(4,9)$ & $0,5(5,4)$ & $0,2(5,1)$ \\
\hline \multicolumn{5}{|l|}{ Networks - RT } \\
\hline Alerting & $109,2(81,6)$ & $101,0(63,6)$ & $80,8(74,4)$ & $96,0(73,5)$ \\
\hline Orienting & $27,7(60,6)$ & $37,5(59,3)$ & $32,0(58,7)$ & $32,7(59,2)$ \\
\hline Conflict & $92,2(85,6)$ & $81,0(60,2)$ & $87,3(56,1)$ & $86,5(66,9)$ \\
\hline \multicolumn{5}{|l|}{ Networks - Errors \% } \\
\hline Alerting & $2,6(9,9)$ & $2,4(5,1)$ & $3,3(6,6)$ & $2,8(7,3)$ \\
\hline Orienting & $0,3(7,0)$ & $0,3(5,9)$ & $0,2(5,7)$ & $0,3(6,1)$ \\
\hline Conflict & $4,6(11,2)$ & $4,4(7,4)$ & $3,4(6,1)$ & $4,1(8,2)$ \\
\hline
\end{tabular}

group with other diagnoses, $p=.09$ and the group without any diagnosis, $p=.06$ ).

\section{Variability measures}

A one-way between groups ANOVA was performed separately for the overall Hit RT and the variability measures (Hit RT SE, variability of SE, Hit RT block change, Hit SE block change). A statistically significant main effect of group was found on the Hit RT SE measure (Table 2 and 3 ). Between group Tukey HSD comparisons revealed that the ADHD group showed significantly larger Hits RT SE than the group without diagnosis and border on significance when compared to the group with other diagnoses $(p=.054)$. No main effect of group was found on the other measures.

\section{Age and FSIQ scores correlation}

A Bonferroni corrected Pearson's correlation analysis was performed between FSIQ scores, age and ANT measures (Table 4). The analysis revealed a high correlation between age and the overall Hit RT and the variability measures, showing that the older the children, the faster they responded, with a higher level of consistency. Table 4 shows that this only applied to the two non-ADHD groups. Correlations between FSIQ scores and the ANT measures were more widespread, including both error and variability measures. Table 4 shows that this only applied to the ADHD group, showing that the lower the FSIQ scores, the less accurate the children responded and with less consistency.

\section{FSIQ score as covariate}

When FSIQ was included as a covariate in the ANOVA analyses, the main effect for group was no longer statistically significant for the overall error measure $(F(2,153)=$ $0,689, p=.504)$ and the Hit RT SE measure $(F(2,153)=$ $0,316, p=.729)$.

\section{Influence of medication}

The group of ADHD children taking central stimulants regularly $(\mathrm{N}=9)$ was compared to the other ADHD children $(\mathrm{N}=36)$ on selected ANT measures (overall errors, Hits RT, Hits RT SE) and FSIQ scores. Bonferroni corrected independent-samples t-test showed no statistically significant difference between the two groups.

\section{Discussion}

The aim of the present study was to characterize patterns of ANT performance in children with an ADHD diagnosis. On the measures of the three attention networks, the results revealed no statistically significant differences between the group of children with ADHD, the group of 
Table 3: A one-way ANOVA showing the difference between the groups on selected ANT variables.

\begin{tabular}{|c|c|c|c|}
\hline & \multicolumn{3}{|c|}{ Main effect of between groups ANOVA } \\
\hline & $D f$ & $F$ & Between \\
\hline \multicolumn{4}{|l|}{ Covariate } \\
\hline FSIQ & 2,154 & $22.66 * * * *$ & $1<2,3$ \\
\hline \multicolumn{4}{|l|}{$\begin{array}{l}\text { Accuracy and error } \\
\text { variables }\end{array}$} \\
\hline Overall errors & 2,154 & $6.77^{* *}$ & $1>2,3$ \\
\hline Wrong respons & 2,154 & $5.58 * *$ & $\mathrm{I}>2,3$ \\
\hline Omissions & 2,154 & $4.54^{*}$ & ns \\
\hline \multicolumn{4}{|l|}{$\begin{array}{l}\text { Consistency and } \\
\text { variability variables }\end{array}$} \\
\hline Hits RT & 2,154 & 1.23 & ns \\
\hline Hit RT SE & 2,154 & $4.4 I^{* *}$ & $1>3$ \\
\hline Variability of SE & 2,154 & .05 & ns \\
\hline Hit RT Block Change & 2,154 & 2.34 & ns \\
\hline Hit SE Block Change & 2,154 & .22 & ns \\
\hline \multicolumn{4}{|l|}{ Networks } \\
\hline Alerting - RT & 2,154 & 2.09 & ns \\
\hline Orienting - RT & 2,154 & .34 & ns \\
\hline Conflict - RT & 2,154 & .35 & ns \\
\hline Alerting - Error & 2,154 & .21 & ns \\
\hline Orienting - Error & 2,154 & .01 & ns \\
\hline Conflict - Error & 2,154 & .34 & ns \\
\hline
\end{tabular}

$*=\mathrm{p}<.05 * *=\mathrm{p}<.01 * * *=\mathrm{p}<.001$

Group: I = ADHD; 2 = Other diagnoses; $3=$ No diagnosis

children with other psychiatric diagnoses and the group of children without any diagnosis. However, the children diagnosed with ADHD showed a lower accuracy score as well as a more variable response pattern (i.e. a higher SE of RT) than the other groups.

The results confirmed the expectation of lower accuracy scores in the ADHD group compared to what was shown in the other two groups. The ADHD group reported more wrong responses and showed a trend towards more omissions errors compared to the non-ADHD groups. The high number of omission errors in the ADHD group indicated a higher level of inattention than in children belonging to the two other groups, a finding that confirms earlier findings in studies using the Conners' CPT $[16,17]$. The results did also support the prediction of high response variability in the ADHD group. However, the variability of SE was not different between the three groups. According to Conners [32], a pattern of higher Hits SE RT than Variability SE suggests a poor consistency of responses that did not change as the test progressed. This supports the idea that problems related to inattention rather than vigilance are characteristic of children with ADHD.

Our findings with respect to vigilance are in conflict with results from studies using CPT, suggesting that loss of vigilance as the test progresses is characteristic of children with an ADHD diagnosis $[12,14,15]$. It is well known that children perform better on tasks with a vivid feedback and on tasks that have an underlying story [30]. The child version of the ANT is more similar to a computer-game with immediate and clear feedback on performance than the Conners' CPT. The ANT includes a character (the fish), a narrative (is hungry, help feed him), and auditory and visual feedback (fish blowing bubbles and wagging its tail as well as exciting sound), and these features have been found to improve the performance on more game-like versions of the CPT [34]. This and the fact that the ANT has just three time blocks compared to six in the CPT, may have made the vigilance measure less sensitive to a core problem of children with ADHD [12,14-16].

The FSIQ score was strongly correlated with both error and variability measures, but only in the ADHD group. When included as a covariate, all differences between the ADHD group and the two other groups became non-sig-

Table 4: Correlations between selected ANT variables within the three groups and for all participants.

\begin{tabular}{|c|c|c|c|c|c|c|c|c|}
\hline & \multicolumn{2}{|c|}{ ADHD definite diagnosis $N=45$} & \multicolumn{2}{|c|}{ Other definite Diagnoses $N=55$} & \multicolumn{2}{|c|}{ Without diagnosis $\mathrm{N}=57$} & \multicolumn{2}{|c|}{ Overall $\mathrm{N}=157$} \\
\hline & Age & FSIQ score & Age & FSIQ score & Age & FSIQ score & Age & FSIQ score \\
\hline \multicolumn{9}{|c|}{ Accuracy and error variables } \\
\hline Overall errors & -.167 & $-.509 * *$ & -.298 & -.255 & -.314 & -.294 & -.164 & $-.455^{* *}$ \\
\hline Wrong response & -.031 & $-.497^{* *}$ & -.111 & -.149 & -.264 & -.152 & -.073 & $-.373^{* *}$ \\
\hline Omissions & -.191 & $-.408^{*}$ & -.315 & -.236 & -.274 & -.277 & -.174 & $-.388 * *$ \\
\hline \multicolumn{9}{|c|}{ Consistency and variability variables } \\
\hline Hits RT & -.164 & -.309 & $-.469 * *$ & -.101 & $-.411 * *$ & -.183 & $-.320 * *$ & $-.235^{*}$ \\
\hline Hit RT SE & -.094 & $-.472 * *$ & -.321 & -.239 & -.235 & -.207 & -.159 & $-.38 I * *$ \\
\hline Variability of SE & .051 & -.084 & .181 & -.054 & .066 & -.036 & .089 & -.041 \\
\hline Hit RT Block Change & .083 & .069 & .287 & -.176 & $.415^{* *}$ & .098 & $.312^{* * *}$ & -.058 \\
\hline Hit SE Block Change & .034 & -.108 & .119 & -.240 & .299 & .009 & .164 & -.100 \\
\hline
\end{tabular}

$*=$ Correlation is significant at the 0.05 level 2 tailed

** = Correlation is significant at the 0.01 level 2 tailed 
nificant. There is an ongoing debate whether or not one should control for IQ in studies of cognitive function in children with ADHD [15,35-37]. Several studies have shown that children with ADHD tend to obtain lower IQ scores than other children [35,37], and that the neurocognitive disorders of ADHD in itself can cause poor performance on intelligence tests [38]. Actually, a meta-analysis found a strong association between ADHD and FSIQ $(d=$ .61) [35]. This is supported by the results in the present study, showing that the highest and most widespread correlations were found in the ADHD group. If reduced IQ is a developmental consequence of the ADHD disorder, then, by controlling for IQ, one may very well control for a part of the disorder $[35,36]$. This has led Barkley $[38,39]$ to argue that it is probably unwise to control for IQ score in studies comparing ADHD groups and controls, and that studies of ADHD should rather report results with and without controlling for IQ scores [40], as done in the present study.

While the IQ scores showed the strongest associations with errors, age was more strongly associated with the Hit RT and variability measures. Age was correlated with faster overall RT in the non-ADHD groups, confirming earlier findings that RT improves with age [30,31]. However, age was not significantly correlated to any of the dependent ANT measures in the ADHD group, suggesting that children with ADHD do not show the expected improvement of RTs as they age. The results revealed no significant group differences on the efficiency and error measures of the three attention networks. These results are in accordance with Booth's [9] findings in a study using the same child version of the ANT as in the present study. However, the results did not support the findings of Konrad et al. [11], who showed a significant deficit in the efficiency of the conflict network. One explanation may be that they used a modified ANT procedure. Rueda et al. [30] found that the fish target used in the present study as well as a paradigm including only valid cues generates a smaller interference effect of incongruent flankers than the arrow target. This implies that the paradigm used in the present study may have made it easier for the children to solve the conflict between the congruent and incongruent flankers than in the study of Konrad and collaborators [11], and may indicate a need for revision of the child version of the ANT in future studies of children with an ADHD diagnosis.

Based on the behavioral measures of the attention networks, one should not exclude the possibility of a characteristic neural activity in children with ADHD, as suggested by Rodriguez [10] and Konrad et al. [11]. From these studies one may argue that children with ADHD use different strategies for completing tasks than their peers, and that behavioral measures are not sensitive enough to detect this difference [11]. However, the high number of errors reported by children with ADHD in the present study may be used to support the idea of a less effective use of strategies in children with ADHD than in their nonADHD peers.

\section{Strengths and weaknesses}

As in all research including children with an ADHD diagnosis, the present results are colored by the high degree of heterogeneity within the diagnostic group. In the present study, information about subgroups of ADHD and symptom load was not included. Both Booth [9] and Rodriguez [10] found a difference between the DSM-IV defined diagnostic subgroups of ADHD on the network measures. On the other hand, Seidman [36] argues that there are more similarities between the subgroups of ADHD than dissimilarities when it comes to measures of cognitive functions. We have calculated the within response variability according to Conners [32]. According to Russell et al. [41], more extended calculations may give more adequate measures of variability and should be considered in further studies.

The main strength of the study was the case-control selected sample of children with ADHD, and that the results probably are less biased by co-morbid problems than clinical studies. However, no child was excluded due to a low FSIQ score, although some of the BCS participants with very low FSIQ score were excluded because they were unable to perform the ANT. The high correlations between the FSIQ score and error and variability measures in the ADHD group indicate that by excluding children with low total IQ scores, one may have excluded a specific group of ADHD children [39].

\section{Clinical implications}

Although there have been several studies of the neuropsychological characteristics and the neural basis of ADHD, the deficits of attention in children with this behavioral diagnosis are still poorly understood. To conduct studies of this complex issue, appropriate neurocognitive models that operationalize different aspects of the attention system are necessary. The attention network theory provides one such model and can be used both in group studies and in the clinical evaluation of individual children. In a neuropsychological examination, the range of variables from the ANT may help to characterize the strengths and difficulties of a child. Studies of the attention networks in children with ADHD may contribute to a better understanding of the disorder and to the development of appropriatetraining and treatment methods [42].

\section{Conclusion}

The results in the present study support the notion that accuracy measures rather than RT measures are sensitive to characteristic deficits in children with ADHD $[12,13]$. 
The results also demonstrate the importance of including accuracy measures and variability measures to extend the sensitivity of the ANT to deficits that characterize children with an ADHD diagnosis. Nevertheless, there is a need of developing the test measures, and to perform studies investigating the clinical significance of the errors and variability shown by children with ADHD.

\section{Competing interests}

The author(s) declare that they have no competing interests.

\section{Authors' contributions}

SA has been responsible for the data analysis and the writing of the manuscript. AJL designed and coordinated the study, supervised the data analysis and the writing process. LS participated in the acquisition of data, discussions about the data analyses and commented on the written drafts of the manuscript. All authors have read and approved the final manuscript.

\section{List of abbreviations}

ADHD: Attention Deficit Hyperactivity Disorder; ANT: Attention Network Test; BCS: Bergen Child Study; CPT: Continuous Performance Test; FSIQ: Full Scale IQ; ODD: Oppositional Defiant Disorder; RT: Reaction time; Kiddie-Sads-PL: Kiddie-Sads-Present and Lifetime Version; WISC-III: Wechsler Intelligence Scale for Children-III.

\section{Acknowledgements}

The present study was supported by the University of Bergen, the Norwegian Directorate for Health and Social Affairs, and the Western Norway Regional Health Authority. We are grateful to the children, parents and teachers who participated in the BCS, and to the BCS project group for making the study possible.

\section{References}

I. Posner MI, Petersen SE: The attention system of the human brain. Annu Rev Neurosci 1990, I 3:25-42.

2. Callejas A, Lupianez J, Tudela P: The three attentional networks: on their independence and interactions. Brain Cogn 2004, 54:225-227.

3. Posner MI, Raichle ME: Images of mind New York: Scientific American Library/Scientific American Books; 1994.

4. Fan J, McCandliss BD, Fossella J, Flombaum JI, Posner MI: The activation of attentional networks. Neuroimage 2005, 26:47I-479.

5. Berger A, Posner MI: Pathologies of brain attentional networks. Neurosci Biobehav Rev 2000, 24:3-5.

6. Fan J, McCandliss BD, Sommer T, Raz A, Posner MI: Testing the efficiency and independence of attentional networks. J Cogn Neurosci 2002, 14:340-347.

7. Posner MI: Orienting of attention. Q J Exp Psychol 1980, 32:3-25.

8. Eriksen BA, Eriksen CW: Effects of noise letters upon the identification of a target letter in a nonsearch task. Percept Psychophys 1974, 16:143.

9. Booth JE, Carlson CL: Cognitive processes of inattention in attention deficit hyperactivity disorder subtypes. The University of Texas at Austin 2003.

10. Rodriguez PD: Attention networks in attention-deficit/hyperactivity disorder subtypes: An event-related potentials study. University of South Carolina, Department of Psychology 2005.

II. Konrad K, Neufang S, Hanisch C, Fink GR, Herpertz-Dahlmann B: Dysfunctional attentional networks in children with atten- tion deficit/hyperactivity disorder: evidence from an eventrelated functional magnetic resonance imaging study. Biol Psychiatry 2006, 59:643-65I.

12. Stins JF, Tollenaar MS, Slaats-Willemse DI, Buitelaar JK, Swaab-Barneveld H, Verhulst FC, Polderman TC, Boomsma DI: Sustained attention and executive functioning performance in attention-deficit/hyperactivity disorder. Child Neuropsychol 2005, I I :285-294

13. Wilding J: Is attention impaired in ADHD? Brit J Dev Psychol 2005, 23:487.

14. Swaab-Barneveld $H$, de Sonneville L, Cohen-Kettenis P, Gielen A, Buitelaar J, Van Engeland $\mathrm{H}$ : Visual sustained attention in a child psychiatric population. J Am Acad Child Adolesc Psychiatry 2000, 39:65I-659.

15. Willcutt EG, Doyle AE, Nigg JT, Faraone SV, Pennington BF: Validity of the executive function theory of attention-deficit/hyperactivity disorder: a meta-analytic review. Biol Psychiatry 2005, 57:1336-1346.

16. Epstein JN, Erkanli A, Conners CK, Klaric J, Costello JE, Angold A: Relations Between Continuous Performance Test Performance Measures and ADHD Behaviors. J Abnorm Child Psychol 2003, 3 I:543.

17. Losier BJ, McGrath PJ, Klein RM: Error patterns on the continuous performance test in non-medicated and medicated samples of children with and without ADHD: a meta-analytic review. J Child Psychol Psychiatry 1996, 37:971-987.

18. Oberlin BG, Alford JL, Marrocco RT: Normal attention orienting but abnormal stimulus alerting and conflict effect in combined subtype of ADHD. Behav Brain Res 2005, I 65: I-I I.

19. Posserud MB, Lundervold AJ, Gillberg C: Autistic features in a total population of 7-9-year-old children assessed by the ASSQ (Autism Spectrum Screening Questionnaire). J Child Psychol Psychiatry 2006, 47:167-175.

20. Heiervang E, Stormark KM, Lundervold AJ, Heimann M, Goodman R Posserud MB, Ullebo AK, Plessen KJ, Bjelland I, Lie SA, Gillberg C: Psychiatric disorders in Norwegian 8- to I O-year-olds: an epidemiological survey of prevalence, risk factors, and service use. J Am Acad Child Adolesc Psychiatry 2007, 46:438-447.

21. Goodman R: The extended version of the Strengths and Difficulties Questionnaire as a guide to child psychiatric caseness and consequent burden. I Child Psychol Psychiatry 1999, 40:791-799.

22. Ehlers S, Gillberg C, Wing L: A screening questionnaire for Asperger syndrome and other high-functioning autism spectrum disorders in school age children. J Autism Dev Disord 1999 , 29:|29-|4|

23. Swanson JM, Kraemer HC, Hinshaw SP, Arnold LE, Conners CK, Abikoff HB, Clevenger W, Davies M, Elliott GR, Greenhill LL, et al: Clinical relevance of the primary findings of the MTA: success rates based on severity of ADHD and ODD symptoms at the end of treatment. J Am Acad Child Adolesc Psychiatry 200I, 40: $168-179$.

24. Goodman R, Ford T, Richards H, Gatward R, Meltzer H: The Development and Well-Being Assessment: description and initial validation of an integrated assessment of child and adolescent psychopathology. J Child Psychol Psychiatry 2000, 4 I:645-655.

25. Hysing M, Elgen I, Gillberg C, Lie SA, Lundervold AJ: Chronic physical illness and mental health in children. Results from a large-scale population study. J Child Psychol Psychiatry 2007, 48:785-792.

26. Kaufman J, Birmaher B, Brent D, Rao U, Flynn C, Moreci P, Williamson D, Ryan N: Schedule for Affective Disorders and Schizophrenia for School-Age Children-Present and Lifetime Version (K-SADS-PL): initial reliability and validity data. J Am Acad Child Adolesc Psychiatry 1997, 36:980-988.

27. Wechsler D: Wechsler Intelligence Scale for Children - III (Norwegian version) Stockholm: Harcourt Assessment; 2003.

28. Fan J: The Attention Network Test. Child edition 200I.

29. Ambrosini PJ: Historical development and present status of the schedule for affective disorders and schizophrenia for school-age children (K-SADS). J Am Acad Child Adolesc Psychiatry 2000, 39:49-58.

30. Rueda MR, Fan J, McCandliss BD, Halparin JD, Gruber DB, Lercari LP, Posner MI: Development of attentional networks in childhood. Neuropsychologia 2004, 42:1029-1040. 
31. Mezzacappa E: Alerting, orienting, and executive attention: developmental properties and sociodemographic correlates in an epidemiological sample of young, urban children. Child Dev 2004, 75: 1373-1386.

32. Conners CK: Conners' Continuous Performance Test (CPT II). Version 5 for Windows. Technical Guide and Software Manual Toronto: MultiHealth Systems Inc; 2000.

33. Wechsler D: Manual for Wechsler Intelligence Scale for Children (Swedish version) 3rd edition. Stockholm: Psykologiforlaget; 1999.

34. Shaw RM: The effect of context on the performance of children with ADHD on a series of computerised tasks and games [abstract]. The Open University 2004.

35. Frazier TW, Demaree HA, Youngstrom EA: Meta-analysis of intellectual and neuropsychological test performance in attention-deficit/hyperactivity disorder. Neuropsychology 2004 18:543-555.

36. Seidman L): Neuropsychological functioning in people with ADHD across the lifespan. Clin Psychol Rev 2006, 26:466-485.

37. Schwean VL, Saklofske DH: WISC-III assessment of children with attention deficit/hyperactivity disorder. In WISC-III clinical use and interpretation: Scientist-practitioner perspectives Edited by: Prifitera A, Saklofske DH. San Diego: Academic Press; 1998:91-II8.

38. Barkley RA: Associated Problems. In Attention-deficit hyperactivity disorder: $A$ handbook for diagnosis and treatment 2 nd edition. Edited by: Barkley RA. New York: Guilford Press; 1998:97-138.

39. Barkley RA: Symptoms, Diagnosis, Prevalence, and Gender differences. In Attention-deficit hyperactivity disorder: A handbook for diagnosis and treatment 2 nd edition. Edited by: Barkley RA. New York: Guilford Press; 1998:56-96.

40. Barkley RA: ADHD and the nature of self-control New York: Guilford Press; 1997.

4I. Russell VA, Oades RD, Tannock R, Killeen PR, Auerbach JG, Johansen $\mathrm{EB}$, Sagvolden T: Response variability in Attention-Deficit/ Hyperactivity Disorder: a neuronal and glial energetics hypothesis. Behav Brain Funct 2006, 2:30.

42. Posner Ml: Progress in Attention Research. In Cognitive neuroscience of attention Edited by: Posner MI. New York: Guilford Press; 2004:3-9.

\section{Publish with Bio Med Central and every scientist can read your work free of charge}

"BioMed Central will be the most significant development for disseminating the results of biomedical research in our lifetime. "

Sir Paul Nurse, Cancer Research UK

Your research papers will be:

- available free of charge to the entire biomedical community

- peer reviewed and published immediately upon acceptance

- cited in PubMed and archived on PubMed Central

- yours - you keep the copyright 